\title{
Fatal ascaris pancreatitis: an uncommon problem in the west
}

\author{
G J Maddern, A R Dennison, L H Blumgart
}

\begin{abstract}
Gastrointestinal parasites, although an uncommon cause of biliary and pancreatic problems in western medicine, can produce fatal complications. A Swiss patient presented with acute pancreatitis, with no evidence of gall stones or history of alcohol abuse. He died after a short fulminant illness. At necropsy, an Ascaris lumbracoides was found impacted within the ampulla of Vater and serves as a reminder that non-indigenous causes of biliary tract obstruction should not be overlooked.
\end{abstract}

Infestation with gastrointestinal parasites is well known in Asian countries and is associated with a well recognised spectrum of biliary and pancreatic complications. ${ }^{1}$ Although a rare source of problems in western medical and surgical practice, it still occurs and a low index of suspicion can contribute to a potentially devastating outcome. We report the case of a patient resident in Switzerland who suffered fatal pancreatitis caused by impaction of an Ascaris lumbracoides in the ampulla of Vater.

\section{Case report}

A 66 year old man presented to his local hospital with an acute onset of diffuse abdominal pain. At that time his serum amylase activity was $5120 \mathrm{U} / 1$ with a lipase value of $10230 \mathrm{U} / \mathrm{l}$. On the basis of

Accepted for publication 2 July 1991

Department of Visceral
and Transplantation
Surgery, Inselspital,
Berne, Switzerland
G J Maddern
A R Dennison
L H Blumgart
Correspondence to:
Professor L H Blumgart,
Department of Visceral and
Transplantation Surgery,
Inselspital, 3010 Berne,
Switzerland.
Accepted for publication
2 July 1991

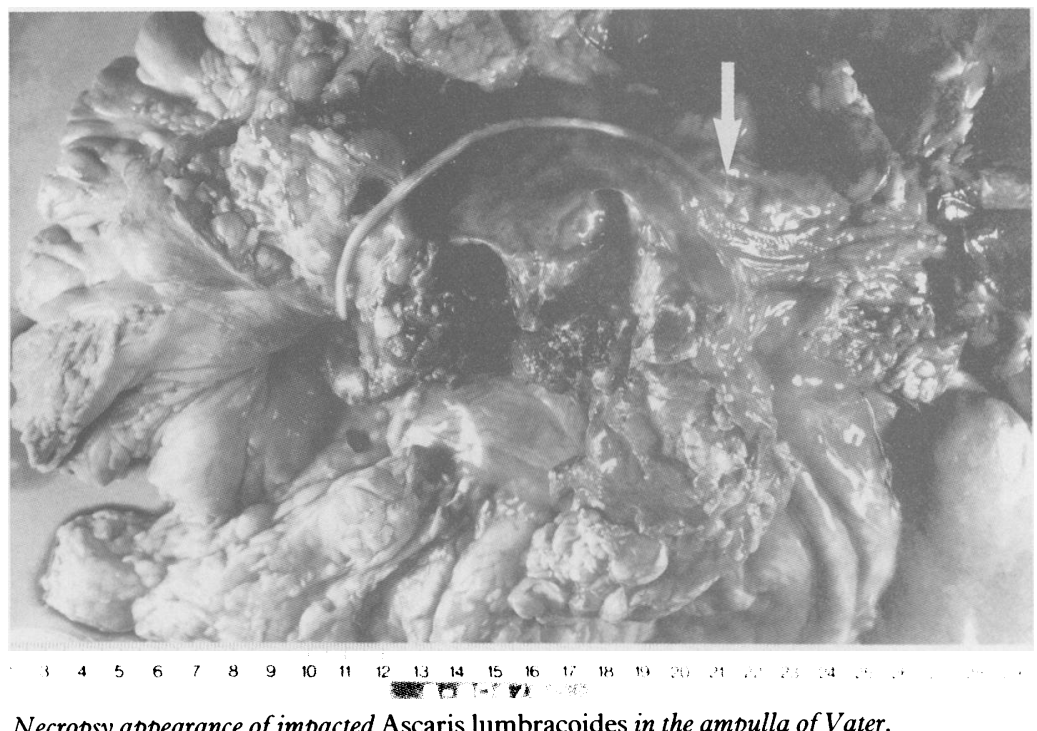

his clinical presentation and these investigations, a diagnosis of acute pancreatitis was made. His condition deteriorated and the following day he was transferred to our hospital where he was found to have a grossly distended abdomen with diffuse abdominal pain.

At the time of transfer his blood pressure was $90 / 50 \mathrm{~mm} \mathrm{Hg}$ with a pulse of $100 /$ minute. He was afebrile and laboratory investigations showed: total white blood cell count slightly raised at 9.9 10\% 1 , a low haemoglobin concentration of $12.9 \mathrm{~g} / 100 \mathrm{ml}$, and a very high neutrophil count of $72 \cdot 5 \%$. Coagulation was abnormal with a Quick of $37 \%$. The calcium concentration was $1.48 \mathrm{mmol} / \mathrm{l}$ and his $\mathrm{pH}$ was $7 \cdot 25$, with a $\mathrm{pO}_{2}$ of $55 \mathrm{~mm} \mathrm{Hg}$ and a creatinine value of $235 \mathrm{mmol} / \mathrm{l}$. Liver enzymes and alkaline phosphatase activities were normal. The patient's serum amylase activity had risen and was now $6155 \mathrm{U} / \mathrm{l}$ and the serum albumin concentration was $20 \mathrm{U} / 1$.

An ultrasound performed at this time showed a normal gall bladder with no dilatation of intraor extrahepatic bile ducts. Because of his extremely poor general condition and, in particular, his severe respiratory complications he was immediately transferred to the intensive care unit and ventilatory support was begun. Unfortunately this, and full inotropic support, proved insufficient to prevent a further deterioration of his condition and he died eight hours after transfer.

A necropsy was performed the following morning and severe necrotising pancreatitis, with generalised necrosis in the retroperitoneum, mesentry, and pericolic regions was found. There was subtotal pancreatic necrosis and on opening the duodenum a $15 \mathrm{~cm}$ long Ascaris lumbracoides was found with its most cephalad segment impacted in the ampulla of Vater (Figure).

\section{Discussion}

Severe pancreatitis in the western world is usually caused by gall stone disease or alcohol abuse. When patients present with pancreatitis but neither of these two underlying causes can be shown, the problem is often attributed to viral infection, drug administration (for example diuretics, steroids), or a variety of causes that are well recognised but extremely difficult to prove on an individual basis.

The patient described falls into this category in that he did not have gall stones or a history of 
alcohol abuse and had not travelled outside western Europe. Furthermore, emergency ultrasound failed to show any intra- or extrahepatic duct dilatation (supported by normal alkaline phosphatase and bilirubin values). While the patient's condition precluded immediate endoscopic retrograde cholangiopancreatography (ERCP) on admission, this would probably have revealed the diagnosis. The impact of ERCP in this or similar cases is difficult to assess, although in Asian countries, where obstruction caused by parasitic infections is much more commonly seen, there is a much more aggressive approach to management.'

Reports of similar cases and also of patients with hydatid disease ${ }^{2}$ and Clonorchis sinensis ${ }^{3}$ are well documented and it is possible that ERCP as an emergency procedure in all patients on the 'off chance' of diagnosing a parasitic and treatable problem can be justified. Indeed, since the limitations of ultrasound are well recognised many centres now routinely perform ERCP (if the patient's condition allows) for diagnostic purposes. This diagnostic approach also facilitates the performance of a papilotomy (and/or nasobiliary drainage) if common bile duct stones are found.

In this group of patients, especially where there is an unusual appearance within the bile duct, it is important not to prejudice adequate treatment by overlooking a possible parasitic aetiology.

1 Dennis MJS, Dennison AR, Morris DL. Parasitic causes of obstructive jaundice. Ann Trop Med Parasitol 1989; 83: obstructive

2 Harris KM, Morris DL, Tudor R, Toghill P, Hardcastle JD. Clinical and radiological features of patients with simple or hydatid cysts of the liver. Br $\mathcal{F}$ Surg 1986; 73: 835-8.

3 Hon PC. The pathology of clonorchis sinensis infestation of the liver. F Pathol Bacteriol 1955; 70: 53-63. 